\title{
Non-permanent English teachers' resilience in constructing professional identity in the remote areas of south Sulawesi
}

\author{
Yunika Upa ${ }^{1 *}$, Concilianus Laos Mbato $^{2}$ \\ ${ }^{12}$ Universitas Sanata Dharma, Indonesia \\ *)Corresponding author, Ðe-mail: yunikayuni735@gmail.com
}

\begin{abstract}
Being a non-permanent English teacher in a remote area is not easy. The non-permanent teachers have to face many challenges. Without having resilience, the teachers can not survive to teach in the area. This study investigated the factors that influenced the resilience of the non-permanent English teachers in building a professional identity in the remote areas of South Sulawesi. The mixed-method explanatory sequential experimental design was used by involving non-permanent English teachers at five schools in the remote area of Tana Toraja, South Sulawesi Province. The RSA Scale questionnaire and interview were used to find out what factors influenced teachers' resilience. The results showed that the challenges faced by non-permanent English teachers made them resilient teachers. Personal resources and contextual resources seemed to play a major role in their growth of resilience. The high resilience of teachers shapes their professional identity, which makes them stay afloat and think that teaching is their calling. This study suggests implications for the education of policymakers and the government in Indonesia, and also for future researchers who are interested in a similar topic may conduct further studies with a broader context.
\end{abstract}

Keywords: Teacher identity, resilience, non-permanent English teacher.

How to Cite: Upa, Y., \& Mbato, C. (2020). Non-permanent english teachers' resilience in constructing professional identity in the remote areas of South Sulawesi. COUNS-EDU: The International Journal of Counseling and Education, 5(4). DOI: http://dx.doi.org/10.23916/ 0020200526440

This is an open access article distributed under the Creative Commons Attribution License, which permits unrestricted use, distribution, and reproduction in any medium, provided the original work is properly cited. (C)2020 by author.

\section{Introduction}

Identity development is the biggest challenge process for teachers (Pearce \& Morrison, 2011). Teacher identity has an important role in teaching and learning (Friesen et al., 2013) and teacher identity development (Rodrigues \& Mogarro, 2019). Johnson et al., (2015) states that 'Teacher identity leads to self-understanding and development of awareness as teachers'. It means that the teacher's identity is complex, and can change from time to time (Richardson \& Watt, 2018). Thus, it can be concluded that the teacher's identity is related to how they see themselves and the work they do. When teachers face many challenges in their teaching job, then over time, their identities may change.

Teacher identity is influenced by two aspects. They are aspects of external experiences (life experiences during teaching) and aspects of internal experiences (emotions and personal factors). Teacher identity is the result of interaction between students, parents, and colleagues while teaching identity is the result of interaction from the teacher's personal experience and the school environment (González-Calvo \& Arias-Carballal, 2017). According to Day (as cited in Schutz \& Hong, n.d., 2018) the teacher's work environment is identical to emotional work. It is caused by high job demands on the teacher. Thus, when a teacher cannot face challenges in his work environment, his identity as a teacher will change. 


\section{COUNS-EDU}

Vol.5, No.4, 2020

Available online: http://journal.konselor.or.id/index.php/counsedu

Upa, Y., \& Mbato, C.

Becoming a teacher in a remote area is not easy, especially for non-permanent English teachers in a remote area of South Sulawesi. There are so many challenges that must be faced by teachers in remote areas. Besides the limited infrastructure in remote areas, teachers also have to deal with limited facilities in the teaching and learning process. Several researchers highlight the challenges faced by teachers in remote areas in Indonesia. Febriana et al., (2018) states that the factors that cause teachers' reluctance to teach in remote areas are "language barrier, parents' mindset about the importance of learning, student competency and students' mindset in learning languages because they are not interested in subject". On the other hand, Prouty (Papua, 2012) mentioned that difficult access to schools is also a reason for the absence of teachers in remote areas. The location of schools in remote areas far from the center of the crowd and inadequate housing facilities that are not met by the government makes teachers unable to survive in the area. Therefore, many teachers feel uncomfortable and ask to move to schools in urban areas. Hidayah \& Tri Marhaeni, (2016) also found that the late payment of teacher salaries resulted in teachers absenteeism in school to carry out the teaching and learning process to find additional work to meet their daily needs. This issue also influenced teachers' motivation for going to teach in school. This situation is a big challenge for the teachers in remote areas which makes many teachers reluctant to teach in the area. It is resulting in a lack of teaching staff in the area. To be able to overcome these challenges, the teacher must have the ability to adapt and overcome existing problems. This ability is called self-resilience. Resilience has a positive influence on the teacher's professional identity (Schutz \& Hong, n.d.). Therefore, when the teacher successfully negotiates his identity, then he will become a resilient teacher.

Resilience was originally used to explain a person's ability to adapt and develop in the face of adversity. Madhie et al., (2015) as cited by (Madihie, 2016) stated that Resilience is part of "personal attribute development in individual". But over the past decade many researchers have developed research on resilience in education, especially for teachers. Many researchers define and conceptualize teacher resilience in various ways. On the other hand, Petterson \& Kelleher as quoted in (Nurwidodo et al., (2017) stated that resilience is a basic contraction that gives strength to help school leaders (teachers, principals, and educators) to rise and develop in the face of adversity. As a teacher, of course, he faces many difficulties in his work. However, in dealing with these difficulties, the success of the teacher depends on how the teacher faces these challenges.

Two factors affect teacher's resilience (C. Mansfield et al., 2014). They are personal resources and contextual resources. Personal resources include motivation, self-efficacy, and emotional competence. To carry out the task as a teacher who faces many challenges in teaching, strong motivation is needed, so that the teacher can hold the teaching position for a long period time. Motivation is the circumstances and factors that encourage teachers' commitment to teaching that enable them to savor teaching so as to achieve their goals (Salifu et al., 2013). Upa \& Mbato, (2020) mentioned that teachers' sense of responsibility towards their students, family, students, and colleagues have an influence on teacher motivation to maintain their commitment in teaching. Besides, teachers also need self-efficacy as confidence and the ability to solve problems in facing various challenges in teaching. Self-efficacy is a personal resource that emphasizes teachers' belief in their ability to solve problems in facing teaching challenges (Le Cornu, 2009). Besides, (Botou et al., 2017) added that one of the challenges teachers must face is the lack of salary they get. When teachers have positive beliefs, this is related to increased motivation and perseverance so that negative thinking about the ability of teachers will decrease (Cassidy, 2015). Lastly, Emotional competence. Emotional competence is a factor that can affect teacher resilience. Resilient individuals use a set of skills well that can help them to control their emotions, attention, and behavior (C. F. Mansfield et al., 2016). Resilient teachers use a set of skills well that can help them to control their emotions, attention, and behavior. According to Chang (2009) teachers will easily experience stress and fatigue when he is unable to manage his emotions. Teachers who lack the ability to regulate emotions have difficulty in establishing and maintaining relationships with others. This can be caused by a variety of reasons including the fact that no one wants to spend time with people who are angry, anxious, worried and anxious at all times. Therefore, teachers in remote areas need awareness and knowledge about how to recognize and control them so that when faced with challenges in teaching they are not easily stressed and tired.

Contextual resources are factors that come from outside the individual such as relationships, school community, and family support. Resilience is formed from strong relationships and mutual trust between teachers, colleagues, students, and leaders. According to Sammons et al., (as quoted in Beltman et al., 2011) "personal, professional, and co-supportive relationships are important for the dynamic process of resilience". Therefore a good relationship between teacher-colleague, teacher-student, and teacher-leader 
will make teachers feel comfortable in the learning process. When teachers experience difficulties in the learning process, teachers will tend to communicate with colleagues or leaders. Through this good relationship, the teacher will also get support from the work environment when facing challenges in the work environment. The second is the school community. According to (C. Mansfield et al., (2014) challenges faced by teachers in the school environment include a variety of student needs, building positive relationships with students and colleagues, limited infrastructure, challenging teaching assignments (curriculum demands and heavy workloads), and parents' demands. Thus, many challenges that must be faced by teachers in schools can affect teacher resilience. When teachers are not able to face the challenges that exist in school, the teachers will tend to feel stressed and cause them to give up and leave their jobs.

Family plays an important role as supporters in facing challenges at work (C. Mansfield et al., 2014). Botou et al., (2017) found that teacher resilience was influenced by strong support built by family members. Family support plays a role in the psychological state of teachers who experience pressure in their work. Through the support provided by the family, psychological well-being will increase with the attention and understanding that give rise to feelings of belonging, increase self-esteem, and positive feelings towards individuals.

Many studies discuss the importance of teacher resilience. Botou et al., (2017) examined the resilience of teachers in Greece who have severe economic crisis conditions. Their findings show that resistance to more than half of primary school teachers is quite high and a small proportion of teachers have very low endurance. Therefore, the economic crisis in Greece caused the resilience of teachers to a moderate level. Furthermore, Arnup \& Bowles (2016) stated that the reason why teachers want to leave their work is stress that affects teacher commitment in teaching. Besides, according to Kharismawan \& Mbato (2020), teachers still want to keep their job because "they enjoy teaching, want to share knowledge, are inspired by their families, get career clarity, want to develop their country, and become valuable in becoming a teacher". Furthermore Nurwidodo et al., (2017) focuses on "Teacher Resilience in Remote Islands. They found that subjects had optimism about their views on life and the profession tended to be more resilient and easily reached a phase of better resilience while some subjects had pessimism about life and professions that they concentrated tended not easily through the resilience phase to reach the next phase. They also found that experience, appreciation of the government/department of education, and the level of achievement of teacher education determine the acceleration phase of the resilience and resilience strategies achieved.

These studies show that resilience has an important role in maintaining teacher commitment in their careers. Research on resilience is very important to understand how teachers show resilience when they not only survive, but thrive, amid challenging conditions (Beltman et al., 2011). Regarding the importance of teacher resilience in facing challenges, there is no research that talks about the resilience of non-permanent English teachers in remote areas in South Sulawesi ( South Sulawesi is in eastern Indonesia, which is far from urban education centers such as Java). The urban education center has supporting facilities in the teaching and learning process while in remote areas, educational facilities are still very limited. In this study, the researchers wanted to find out more about what factors affected nonpermanent English teachers resilience in constructing professional identity in the remote areas of South Sulawesi.

\section{Method}

This study utilized mixed-methods research where it involved gathering quantitative and qualitative data to generate additional insights beyond the information provided and to understand the research problem by triangulating qualitative data in the form of descriptive detail with quantitative data in the form of numbers (Creswell \& Creswell, 2018). The explanatory sequential mixed-method was used in this method by using quantitative data to explain the relationships that were found in qualitative data. It aims to strengthen the results of qualitative research.

The researchers collected data from 6 non-permanent English teachers in 5 schools in the remote areas of South Sulawesi. The study was conducted from September 2019 to January 2020. These teachers were non-permanent English teachers who had the teaching experiences from 2 to 7 years in the remote area of South Sulawesi. The teachers consisted of 2 males and 4 females. The researchers collected data by using three instruments. They were observation, questionnaire, and interview. 


\section{Data collection}

Quantitative data was gathered by distributing a questionnaire to six non-permanent English teachers in the remote area of South Sulawesi. The Resilience Scale for Adults (RSA) from Friborg (2005) was adopted to collect quantitative data. The questionnaire consists of 33 items in the form of a close-ended question (the Likert scale type of questions). The RSA scale consists of 6 dimensions to assess teacher's resilience: the first, Personal strength, with two subscales: Perception of self consists of 6 items (e.g., "I trust completely/I often doubt about My judgments and decisions in teaching at remote area") and Perception of the professional future consists of 4 items (e.g., "I feel my future looks very promising/uncertain"). Second, Structured style constitutes 4 items (e.g., I am good at organizing my time/wasting my time). Third, Social competence consists of 6 items (e.g., I enjoy being together with other people/ by myself). Forth, Family cohesion consists of 6 items (e.g., My family is characterized by disconnection/healthy coherence). Fifth social resources consist of 7 items (e.g., I can discuss personal issues with no one/friends). The participants were asked to answer the questions using a five Likert scale ( $1=$ strongly agree; $2=$ agree; $3=$ neutral; $4=$ agree; $5=$ strongly disagree). The teachers were asked to give their perceptions about what factors affected their resilience to teach in the remote area. This questionnaire has been tested for validity and reliability by (Demir Polat \& ISKENDER, 2018) by distributing to 581 teachers working in Bursa, Sakarya, and Yalova provinces of Turkey. The questionnaire consisted of 33 items and consisted of 5 Likert-point scales, with responses ranging from "strongly disagree" to "strongly agree", to assess the variables associated with each teacher's resilience. The trial results showed that all items are valid (include number) and the instrument is considered reliable (include number).

Qualitative data was used to expand quantitative data. The six teachers were interviewed by using in-depth interviews and focused on the factors that affect teachers' resilience to teach in the remote area. The researchers explored information from the teacher based on the questionnaire that they had filled out. Open-ended questions were used to enable teachers to voice their experiences without being limited by the perspective of the researcher or previous research findings. To ensure answers from interviewees, researchers conducted interviews twice. Observations were used to confirm the answers of non-permanent English teachers in the questionnaire and interview. Observation is an important source in this research, which includes challenges faced by teachers in remote areas. The researchers noted the important things during the observation. The Observations were made twice in 5 schools.

\section{Data analysis}

Quantitative data were analyzed by using descriptive analysis. The analysis was conducted to see the characteristics of each variable in the study. Qualitative data were analyzed by transcribing the audio recording, typing field data, and organizing the data into different types depending on the source of information. Next, the researchers code all the data and applied the coding process to describe the informants, categories, and themes to be analyzed. In the end, the researchers described the theme to be brought into the narrative.

\section{Results and Discussions}

The results showed that even though many challenges must be faced by non-permanent English teachers to teach in the remote area, they were supported by personal resources and contextual resources that made them becoming resilient teachers.

\section{Quantitative Data Analysis}

The following table presents the results of the survey, regarding the factors that influence teacher resilience, namely perception of self (table 1), perception of future (table 2), structured style (table 3): As indicated in the table; 1, all participants showed high agreement for six statements (ranging from mean 4.17/Item 1 to mean 4.50/Item 5) about the personal strength/perception of self dimension. They strongly agreed that they always found solutions when unexpected things happened in teaching (Item 1/Mean 4.17) and also knew how to solve personal problems in teaching (Item 2/Mean 4.33), and found something that could help them to develop in difficult times (Item 5/Mean 4.50). This indicates that the non-permanent English teacher teachers were able to control their emotions and found the right solution when dealing with problems in teaching. Besides, they acknowledge that they believed in their ability to teach (Item 3/Mean 4.17), trust assessment and decisions in teaching (Item 4/Mean 4.50), and managed to reach an agreement with the events experienced (Item 6/Mean 4.33). Positive overall responses of non-permanent English 
teachers to dimension of the perception of personal strength/perception of self the importance of emotional competence when the teacher is confronted with the difficult times experienced by the teacher.

Table 1. Personal Strength/Perception of Self

\begin{tabular}{lll}
\hline No & Statement & Mean \\
\hline $\mathbf{1}$ & $\begin{array}{l}\text { When something unforeseen happens in my teaching at remote area I always find a } \\
\text { solution }\end{array}$ & 4.17 \\
\hline $\mathbf{2}$ & I know how to solve my personal problems in teaching & 4.33 \\
\hline $\mathbf{3}$ & I strongly believe my abilities in teaching & 4.17 \\
\hline $\mathbf{4}$ & I trust completely my judgments and decisions in teaching at remote area & 4.50 \\
\hline $\mathbf{5}$ & In difficult periods I have a tendency to find something good that help me thrive & 4.50 \\
\hline $\mathbf{6}$ & I manage to come to terms with events in my life that I can't influence & 4.33 \\
\hline & \multicolumn{1}{c}{ Mean Score of Perception of Self } & 4.33 \\
\hline
\end{tabular}

Table 2. Personal Strength/Perception of Future

\begin{tabular}{lll}
\hline No & Statement & Mean \\
\hline $\mathbf{7}$ & My plans for the future in my teaching in remote area are possible to accomplish & 4.33 \\
\hline $\mathbf{8}$ & I know how to accomplish My future goals in my teaching in remote area & 4.17 \\
\hline $\mathbf{9}$ & I feel that my future in teaching in the remote area looks very promising & 4.33 \\
\hline $\mathbf{1 0}$ & My goals for the future in my teaching at remote area are well thought through & 4.33 \\
\hline & Mean Score of Perception of Future & 4.29 \\
\hline
\end{tabular}

Table 2 shows the average responses of the non-permanent English teachers to the 4 types of statements regarding the dimensions of perception of future (Item 7-Item 10). Items 7, 9, and 10 showed the highest average (4.33) and perceptions about the future in remote areas have the lowest mean (4.17). The non-permanent English teachers showed high confidence in everything they planned for their future in teaching in the remote areas that can be achieved (Item 7/Mean 4.33). In addition, the non-permanent English teachers believed that the future of teaching in the remote areas was very promising (Item $9 /$ mean 4.33). The contribution of self-assessment (Item 10) to their goals in teaching in the remote areas showed that they have thought it through carefully. It seems that teachers did not still have positive beliefs about their plans and goals for teaching in remote areas. The lowest response to this group of questions is item 8 (mean 4.17) where the non-permanent English teacher showed a positive attitude towards their own self-assessment in how to achieve their future goals in teaching in the remote areas. Overall the nonpermanent teachers showed a positive attitude towards the dimensions of their self-perception in teaching in remote areas.

Table 3. Structured Style

\begin{tabular}{lll}
\hline No & Statement & Mean \\
\hline $\mathbf{1 1}$ & I am at my best in my teaching in remote are when I Have a clear goal to strive for & 3.83 \\
\hline $\mathbf{1 2}$ & When I start on new things/projects in my teaching I prefer to have a thorough plan & 3.67 \\
\hline $\mathbf{1 3}$ & I am good at Organizing my time in teaching & 4.33 \\
\hline $\mathbf{1 4}$ & Simplify my everyday life in Rules and regular routines in teaching in remote area & 4.50 \\
\hline & Mean Score of Structured Style & 4.08 \\
\hline
\end{tabular}

Table 3 shows the high agreement of the non-permanent English teachers on the 4 attitude statements about structure styled dimensions. The highest agreement was found in item 14. The nonpermanent English teachers recognized that rules and routines in teaching in the remote areas simplify their daily lives (Mean 4.50). The second highest agreement is shown in students' responses to item 13 (Mean 4.33). The non-permanent English teachers did not continue to agree that they were good at managing their time in teaching. The third highest agreement is shown in item 11. The non-permanent English teachers agreed that they were in the best condition in teaching in the remote areas when they had clear goals to strive for (Mean 3.83). Although it was still high, students' responses to the overall plan when they started something new showed the lowest mean (Mean 3.67). 
Table 4. Social Competence

\begin{tabular}{lll}
\hline No & Statement & Mean \\
\hline $\mathbf{1 5}$ & I enjoy being Together with other people & 4.33 \\
\hline $\mathbf{1 6}$ & To be flexible in social settings Is really important to me & 3.83 \\
\hline $\mathbf{1 7}$ & New friendships are something I make easily & 4.50 \\
\hline $\mathbf{1 8}$ & Meeting new people is Something I am good at & 3.83 \\
\hline $\mathbf{1 9}$ & When I am with other I easily laugh & 4.17 \\
\hline $\mathbf{2 0}$ & For me, thinking of good topics for conversation is easy & 3.83 \\
\hline & Mean Score of Social Competence & 4.08 \\
\hline
\end{tabular}

Three statements show the same level of agreement of non-permanent English teachers in table 4 (Items 16, 18, \& 20/Mean 3.83). The non-permanent English teachers were pointing out that for them being flexible was very important in social relationships (Item 16). Besides, meeting new people was something they were good at. This indicates that they were not rigid when meeting new people. They also admitted that thinking about a good topic of conversation was something that was easy for them. In item 13 (Mean 4.17) the non-permanent English teachers admitted that they laughed easily when they were together with others. This shows that they were able to socialize well in social relationships. They also showed a very high agreement (Mean 4.33) about enjoying being with others. Item 17 shows the highest agreement that establishing a relationship with someone new was easy for them (Mean 4.50). The positive response of the non-permanent English teachers in the remote areas to the social competence dimension confirmed that establishing good social relationships around teachers is very important in maintaining their commitment to teach in the remote areas.

Table 5. Family Cohesion

\begin{tabular}{lll}
\hline No & Statement & Mean \\
\hline $\mathbf{2 1}$ & My family's understanding of what is important in life is Very similar to me & 4.00 \\
\hline $\mathbf{2 2}$ & I feel very happy with my family & 5.00 \\
\hline $\mathbf{2 3}$ & My family is characterized by Healthy coherence & 5.00 \\
\hline $\mathbf{2 4}$ & $\begin{array}{l}\text { Keeps positive outlook on the future In difficult periods in my teaching at remote } \\
\text { area }\end{array}$ & 4.67 \\
\hline $\mathbf{2 5}$ & Facing people, our family acts Loyal towards one another & 4.33 \\
\hline $\mathbf{2 6}$ & In my family we like to Do things together & 4.33 \\
\hline & $\quad$ Mean Score of Family Cohesion & 4.55 \\
\hline
\end{tabular}

As indicated in Table 5, all participants showed very high agreement for the six statements (ranging from Mean 4.00/Item 21 to Mean 5.00/Item 26) about the family cohesion dimension. Two statements indicated the same level of student agreement (Items $22 \& 23 /$ Mean 5.00). They strongly agreed that they were happy with their family (Item 22). They also showed the highest agreement (Item 23) regarding healthy relationships in their families. Besides, they showed that they were able to maintain a positive outlook when they were in a difficult time (Item 24/Mean 4.67). Items $25 \& 26$ showed the same level of agreement with the non-permanent English teachers (Mean 4.33). The non-permanent English teachers showed that they agreed to be loyal to each other in their family (item 25). On the other hand, they also strongly agreed that in doing everything they did it together in the family (item 26). Although it was still very high, the responses of the teachers were not fixed to the similarity of understanding they had with the family about what was important in life showed the lowest average (Mean 4.00). The overall positive response of non-permanent English teachers to the family cohesion dimension confirmed that a good relationship between family and non-permanent English teachers made a very important contribution in maintaining their commitment to teaching in the remote areas. 
Table 6. Social resources

\begin{tabular}{lll}
\hline No & Statement & Mean \\
\hline $\mathbf{2 7}$ & I can discuss personal issues in my teaching with My colleague/family members & 3.50 \\
\hline $\mathbf{2 8}$ & $\begin{array}{l}\text { Those who are good at encouraging me in my teaching at remote area are Some close } \\
\text { friends/colleague/ family members }\end{array}$ & 4.17 \\
\hline $\mathbf{2 9}$ & The bonds among my colleague is strong & 4.00 \\
\hline $\mathbf{3 0}$ & I am informed right away When a family member experiences a crisis/emergency & 4.50 \\
\hline $\mathbf{3 1}$ & I get support from Friends/ family, colleague/family members & 4.33 \\
\hline $\mathbf{3 2}$ & When needed, I have Always someone who can help me & 4.00 \\
\hline $\mathbf{3 3}$ & My close friends/ colleague/ family members Appreciate my qualities & 4.00 \\
\hline & \multicolumn{2}{c}{ Mean Score of Social Resources } \\
\hline
\end{tabular}

The non-permanent English teachers agreed that when family members experienced an emergency problem, they were immediately notified by their family showing the highest average (Item 30/Mean 4.50) and discussed personal problems with family members and colleagues (Item 27) lowest average (3.50). They also showed high agreement regarding support from friends, family, and colleagues (Item 31/Mean 4.33). In item 28 the non-permanent English teachers showed high agreement (mean 4.17) regarding close friends, colleagues, and family members who always gave encouragement to them for teaching in the remote areas. Three statements showed the same level of agreement with the non-permanent English teachers (Items 29 \& 32/Mean 4.00). The non-permanent English teacher showed strong agreement about the strong bond between colleagues and them (Item 29). It appeared that the non-permanent English teachers able to build good relationships between colleagues, family, and close friends. They also showed that when they needed something, they always had people who could help them (Item 33). Positive responses from the non-permanent English teachers to the social resources dimension emphasized the importance of establishing positive relationships between the non-permanent English teachers, family, colleagues, and close friends in maintaining teachers' commitment to teaching in the remote areas.

\section{Qualitative data analysis}

Qualitative data strengthened the findings from quantitative data on factors that affect the non-permanent English teachers' resilience in constructing professional identity in the remote areas. The results showed that non-permanent English teachers in the remote area were teachers who had teaching experience for two to seven years. They are indigenous people in the remote area. Initially they were hesitant to teach in the area because there were many challenges they had to face. From the results of observations we found that to reach the remote area it was taken approximately 6 hours and must pass through a mountain and a forest. Furthermore, we found that the challenges that must be faced by non-permanent English teachers in the remote areas were cellular networks were, only available in certain places and only available from 07:00 am to 7:00 pm; there was no internet network and electricity was only available from $7 \mathrm{pm}$ to $7 \mathrm{am}$. There were limited textbooks for the students to study. Furthermore, students were still not fluent in Indonesian which caused teachers to use three languages when teaching English (local language, Indonesian, and English). There were also late payments of salaries for approximately one year and the limited number of teachers causing teachers to teach about 4 subjects. These situations were worsened by the lack of parental knowledge about the importance of education for children, and the limited facilities in the school.

The number of challenges that must be faced by the teachers in the remote area make the teachers in the urban area reluctant to come to teach in the remote area school. Even when there are teachers who come to teach from urban areas, none of them can survive to teach in the remote area. They prefer to return to the urban area to teach which results in a lack of the teaching staff in the remote area. Despite the many challenges faced by non-permanent teachers in the remote area the data show that non-permanent English teachers are resilient teachers. It is influenced by personal resources and contextual resources.

\section{Personal resources Motivation}

For each non-permanent teachers, motivation seems to occur before becoming non-permanent teachers in the remote area. In this case, non-permanent teachers have an ambition to develop their area through teaching even though they must be confronted by limited infrastructures and facilities. They hope education can be further developed by the presence of native teachers who teach in the area. They also 
persisted in teaching in the area because there were no teachers who wanted to come to teach there because of the limited infrastructure and the lack of facilities in the learning and teaching. They said that "If we want to wait for others to come for teaching in this remote area, it will be very difficult. So who will teach the students here beside us as natives " (Teacher-01, Teacher-03, Teacher-04, \& Teacher-06). Besides, sometimes they felt compassionate to students who had traveled a distance of about 7 kilos by walking from home but when they arrived at school, the students only came for playing because no teacher came to teach. The non-permanent teachers also had to travel more or less than 5 hours to urban areas to access the internet to get the learning resources for the students even though they had to go through the forest.

\section{Self-efficacy}

The non-permanent English teachers seemed to have high confidence in a better future and their ability to face challenges. This is manifested in the actions of non-permanent teachers who continue to utilize simple learning media but could arouse students' enthusiasm in learning. Although when teaching English they had to use 3 languages (local languages, Indonesian and English) but they believed that their efforts would not be in vain in educating them. One thing that the non-permanent English teachers often experienced was that they had to handle the whole classes because no other teachers were present. They never complained and just gave up. The non-permanent English teachers gave assignments and controlled them one by one to their respective classes. Even though sometimes their income as non-permanent English teachers were not comparable to their dedication, they still insist to continue teaching for the sake of their students. They also had a positive belief that even though they often experienced delays in salary payment but they believed that behind the difficulties there were separate blessings that God would always provide for them. In addition, with their dedication, they believed that one day they would definitely be civil servants. The most impressive thing for non-permanent English teachers was that despite the limited school staff and the lack of school facilities in the teaching and learning process, it made them able to continue to process and could even produce outstanding alumni and not inferior to students in an urban area. Besides, the high confidence of the non-permanent English teachers made them wanting to prove for many people that remote areas were not a barrier for them to create quality alumnus.

\section{Emotional Competence}

Experience while teaching in the remote area showed that the non-permanent English teacher was very understanding of emotions within themselves. They were able to channel their emotions in the right way. One thing that showed that they had a good emotional regulation was when the non-permanent English teachers faced many challenges in terms of geographical, social, and challenges in the teaching and learning process. When first teaching, the non-permanent English teachers seemed to be aware that changing the mindset of parents about the importance of education for their children was not easy, but by continuing to approach the parents it can be changed slowly. Besides, when the non-permanent English teachers faced students who underestimate the teachers' skill, the teachers were not tempted by emotion and did not give up even though the teachers felt disappointed with the students' attitude. But the teachers kept thinking that I am a teacher who will be a role model for my students, so whatever the challenges and problems I experience, I have to face them firmly. The problems were able to make the teachers develop more and make the problem as motivation to learn more about many things besides teaching. They learned a lot that whatever problems they faced, they tried to calm down and found a way out of events that occurred and also in dealing with problems they must be professional and not easily ignited by emotion.

\section{Contextual resources Relationship}

A good relationship between the non-permanent English teachers, students, colleagues, and leader looked very well. When the non-permanent English teachers faced problems in the teaching and learning process, they tend to discuss it with their colleagues and superiors for finding solutions to the problems they faced. Besides, the non-permanent English teachers and colleagues worked hand in hand to provide understanding to parents of the importance of education for their children. They provided mutual support in realizing educational development in the remote area, so that they can create quality alumnus who were not inferior to students in the urban area. When the non-permanent English teachers teaching, the students were enthusiastically welcome them to class. Even though surrounded by limited facilities in learning, the students felt comfortable and happy when learning because of the creativity of the teachers in creating a good atmosphere in the classroom for them. A good relationship between the non-permanent English 
teachers, students, colleagues, and leader made the teachers feeling comfortable and reluctant to leave their profession as teachers in a remote area.

\section{School Community}

The non-permanent English teachers seem comfortable staying in the remote area to teach because they were influenced by the school community. They felt comfortable being teachers because the students were obedient and more respect them as teachers. They saw the difference when they taught the students in urban areas with those in the remote area. Every morning they had to wake up at 6 am and walked to school but when they entered the classroom to teach, their fatigue immediately disappears. It was because of the enthusiasm of the students to learn. Solidarity and cooperation were also considerations to stay afloat in teaching in the remote area. Besides, the parents' demands and mandated curriculum did not burden them, but made them realized that it was challenging for them to develop themselves to be better in the future. On the other hand they also thought that teaching was their soul calling.

\section{Family Support}

The family support that the non-permanent English teachers became an encouragement for them to continue teaching in remote areas. Even though initially the non-permanent English teachers aware that salaries to become non-permanent teachers were not many and sometimes experienced late payment of salaries by more than one year, the family continued to support them to continue serving as teachers. Their families also never complained about the income that they got. They made the family a place to lean back when they faced problems at school. Besides, the family encouraged the non-permanent English teachers to prioritize in teaching the students than participating in community activities that coincide with the teaching and learning process. The high level of family support that the non-permanent English teachers got, making their psychological well-being and self-confidence increase which made them stay afloat to become non-permanent English teachers in the remote area.

\section{Discussion}

The researchers found interesting findings in this study. In this study, the researchers found that even though the non-permanent English teachers experienced the late payment of their salaries for more than one year, it did not make them to give up and leave their profession as non-permanent teachers in the remote areas. They still came with enthusiasm to carry out the teaching and learning process at school, even though sometimes they felt their dedication was not worth the income they get. This finding refutes the study of Hidayah \& Tri Marhaeni, (2016)who stated that late payment of teacher salaries results in the absence of teachers in schools to conduct teaching and learning. Their absence was because they had to find additional work to meet their daily needs. Furthermore, although the non-permanent English teachers had to travel long distances to school through difficult access, it does not dampen their spirits. They say that their feelings will disappear when they see the students' enthusiasm for learning when they entered the classroom. This is inversely proportional to the findings of Prouty (2012) which states that difficult access to schools is also a reason for the absence of teachers in remote areas.

In this study, the researchers also found findings that support the findings of previous studies. The researchers found that the non-permanent English teachers highly motivated in maintaining their commitment to teaching in the remote areas. This was influenced by their ambition to develop education in their area. Besides, responsibility for the students was the factor that most influences teachers' motivation. The absence of teachers from urban areas who was able to survive to teach in the area that makes the teachers chose to survive in advancing the education of students in the area. These findings support the findings of Upa \& Mbato, (2020)which stated that teachers' sense of responsibility towards students has an influence in increasing teacher motivation to maintain their commitment in teaching. Furthermore, Le Cornu, (2009)states that self-efficacy is a personal resource that emphasizes teachers' beliefs in their ability to solve problems in facing teaching challenges. It seemed that teachers do not still have high self-efficacy in building their resilience in remote areas. This is manifested in the high confidence that they have about the better future and their ability to face challenges in the remote areas. When teachers have positive beliefs, this is related to increased motivation and perseverance so that negative thinking about the ability of teachers will decrease (Cassidy, 2015). The high self-efficacy of the nonpermanent English teachers contributes to their ability to face and adapt to life's challenges and pressures that they experienced in the remote area.

On the other hand, emotional intelligence as a factor in the non-permanent English teachers contributed to their ability to face or adapt to life's challenges and pressures. The results showed that the 
non-permanent teachers were able to control their emotions well in dealing with the problems they experienced. It showed that the non-permanent teachers who were resilient used a set of skills well that could help them to control their emotions, attention, and behavior (C. F. Mansfield et al., 2016). Skills in managing emotions made the teachers becoming skilled in breaking away from negative feelings, so that the pressure and stress that arises when facing a problem minimized. The non-permanent teachers who have high emotional intelligence make themselves able to manage the stresses and stress they experience so that they become resilient teachers.

In contextual resources, relationship plays an important role in shaping teachers' resilience. The non-permanent teachers in this study indicate that a good relationship that established among the nonpermanent English teachers and colleagues, leaders, and students were able to provide a sense of comfort for the teachers. Support among colleagues, leaders, and the non-permanent teachers in dealing with problems and advancing education in the remote areas showed that the non-permanent teachers were able to build good social relationships with people around them so that it builds their resilience. This finding is supported by the findings of Sammons et al., (As cited in Beltman et al., 2011) "Personal, professional, and supportive relationships are important for dynamic resilience processes". A good relationship between non-permanent teachers, colleagues, and leaders provided benefits for the non-permanent teachers in improving psychological well-being and also adjustment by providing a sense of belonging, clarifying selfidentity, increasing self-esteem and reducing stress.

Besides, the researchers also found that the non-permanent English teachers have family support which could increase their resilience. Specifically, in the aspects of emotional support, families give attention, trust, and expressions of empathy. This is evident from the recognition of precarious teachers stating that family support is an encouragement for them to continue teaching in remote areas. This finding supported by Botou et al., (2017) study that stated that teacher endurance is influenced by strong support built by family members. The high level of family support that the non-permanent English teachers got, making their psychological well-being and self-confidence increase, which made them stay afloat to become non-permanent English teachers in the remote area.

The results of this study also show that teachers maintain their commitment in teaching because they liked teaching, wanted to develop education in their areas, and shared knowledge with children. These findings confirm the findings of Kharismawan \& Mbato, (2020) who found that teachers still want to keep their jobs because 'they enjoy teaching, want to share knowledge, are inspired by their families, get career clarity, want to develop their country, and become valuable in being a teacher'. The results of this study also show that teachers maintain their commitment in teaching because they liked teaching, wanted to develop education in their areas, and shared knowledge with children. These findings confirm the findings of Kharismawan \& Mbato, (2020) who found that teachers still want to keep their jobs because 'they enjoy teaching, want to share knowledge, are inspired by their families, get career clarity, want to develop their country, and become valuable in being a teacher'. Furthermore, these findings also show that the way teachers negotiate themselves in facing challenges in remote areas shows that they are tenacious teachers. This is due to the factor of personal resources and contextual resources contributing to teachers in facing challenges in remote areas. This finding supports the research of C. Mansfield et al., (2014). They stated that teacher resilience is influenced by two factors, namely personal resources and contextual resources.

Research on resilience is very important to understanding on how teachers show resilience when they not only survive, but thrive amid challenging conditions (Beltman et al., 2011). This research emphasized that the way of the non-permanent English teachers deal with challenges in the remote areas showed that they have high resilience. The high resilience of non-permanent English teachers in remote areas contributes positively in constructing their identities so they can maintain their commitment in teaching in remote areas. It also influenced by personal resources and contextual resources. This is in line with Schutz \& Hong, n.d., (2018) which states that Resilience has a positive influence on the teacher's professional identity. Therefore, when the non-permanent teachers successfully negotiate their identity, they will become a tenacious teacher. They realized that whatever challenges they faced, it would shape them into better individuals.

This research has several weaknesses. One of the weaknesses of this study is that respondents who were limited to the non-permanent English teachers, so that this study is unable to see the dynamics of selfresilience in teachers who have the status of Civil Servants. For future researchers who will conduct research, we suggest using other methods in data collection, larger population instruments and varied 
samples taking into account the environmental, social, and cultural conditions of the subjects to simplify the research. This research is expected to provide non-permanent teachers with information about ways to develop self-resilience strategies. The school is expected to make policies or programs in schools that can maintain the level of self-resilience of teachers in their schools. This research is also expected to provide information to the public, especially for those who are in close contact with teachers on the importance of social support provided to teachers, especially for the non-permanent teachers, regarding their level of resilience. It is also hoped that the government will not turn a blind eye to the welfare of non-permanent teachers in remote areas.

\section{Conclusions}

When looking at the lives of English teachers not being settled in remote areas, they were experiencing various challenges that can disrupt their psychological health if they did not counterbalance with resilience. Besides geographical challenges, they also experienced challenges related to students' character, parents' demands, limited teaching staff, late payment of salaries, limited facilities, language barriers, and parents' mindset about the importance of education. However, these challenges seem to be overcome by the emergence of personal resource factors which include motivation, self-efficacy, and emotional competence; and contextual resources including relationships, school community, and family support in them. The high resilience of non-permanent English teachers in remote areas contributes positively that constructs their identities so that they can maintain their commitment in teaching in remote areas.

\section{References}

Arnup, J., \& Bowles, T. (2016). Should i stay or should i go? Resilience as a protective factor for teachers' intention to leave the teaching profession. Australian Journal of Education, 60(3), $229-244$. https://doi.org/10.1177/0004944116667620

Beltman, S., Mansfield, C., \& Price, A. (2011). Thriving not just surviving: A review of research on teacher resilience. Educational Research Review, 6(3), 185-207. https://doi.org/10.1016/j.edurev.2011.09.001

Botou, A., Mylonakou-Keke, I., Kalouri, O., \& Tsergas, N. (2017). Primary School Teachers' Resilience during the Economic Crisis in Greece. Psychology, 08(01), 131-159. https://doi.org/10.4236/psych.2017.81009

Cassidy, S. (2015). Resilience building in students: The role of academic self-efficacy. Frontiers in Psychology, 6(NOV), 1-14. https://doi.org/10.3389/fpsyg.2015.01781

Creswell, J. W., \& Creswell, J. D. (2018). Research and Design Qualitative, Quantitative and Mixed Methods Approaches. In Thousand Oaks California.

Demir Polat, D., \& I SKENDER, M. (2018). Exploring Teachers' Resilience in Relation to Job Satisfaction, Burnout, Organizational Commitment and Perception of Organizational Climate. International Journal of Psychology and Educational Studies, 5(3), 1-13. https://doi.org/10.17220/ijpes.2018.03.001

Febriana, M., Nurkamto, J., Rochsantiningsih, D., \& Muhtia, A. (2018). Teaching in Rural Indonesian Schools: Teachers' Challenges. International Journal of Multicultural and Multireligious Understanding, 5(5), 11. https://doi.org/10.18415/ijmmu.v5i5.305

González-Calvo, G., \& Arias-Carballal, M. (2017). A teacher's personal-emotional identity and its reflection upon the development of his professional identity. Qualitative Report, 22(6), 1693-1709.

Hidayah, I., \& Tri Marhaeni, P. A. (2016). Reinforcement of professional teacher candidates in Indonesia through program of graduates educating in the frontier, outermost, and disadvantaged regions (SM3T). International Journal of Research in Education and Science, 2(1), 166-171. https://doi.org/10.21890/ijres.02425

Kharismawan, P. Y. (2020). Teachers Attrition in Influencing Teachers 'Decision Making : The View of Seven Early Career English Teachers. https://doi.org/10.4108/eai.20-9-2019.2292099

Le Cornu, R. (2009). Building resilience in pre-service teachers. Teaching and Teacher Education, 25(5), 717723. https://doi.org/10.1016/j.tate.2008.11.016

Madihie, A. (2016). Resilient therapy as an expansion of counselling services in working with the vulnerable clients. COUNS-EDU| The International Journal of Counseling and Education, 1(1), 22. 
https://doi.org/10.23916/22-28.0016.11-i2b

Mansfield, C., Beltman, S., \& Price, A. (2014). Im coming back again! the resilience process of early career teachers. Teachers and Teaching: Theory and Practice, 20(5), 547-567. https://doi.org/10.1080/13540602.2014.937958

Mansfield, C. F., Beltman, S., Broadley, T., \& Weatherby-Fell, N. (2016). Building resilience in teacher education: An evidenced informed framework. Teaching and Teacher Education, 54, 77-87. https://doi.org/10.1016/j.tate.2015.11.016

Nurwidodo, N., Rahardjanto, A., Husamah, H., Mas'odi, M., \& Mufrihah, A. (2017). Teacher Resilience in Remote Islands Area: A Case Study in Small Pagerungan Island Sumenep Regency, Indonesia. Journal of Education and Learning (EduLearn), 11(1), 47. https://doi.org/10.11591/edulearn.v11i1.4669

Papua, W. (2012). "W E L IKE B EING T AUGHT ” A S TUDY ON T EACHER A BSENTEEISM.

Pearce, J., \& Morrison, C. (2011). Teacher Identity and Early Career Resilience: Exploring the Links. Australian Journal of Teacher Education, 36(1). https://doi.org/10.14221/ajte.2011v36n1.4

Rodrigues, F., \& Mogarro, M. J. (2019). Student teachers' professional identity: A review of research contributions. Educational Research Review, 28(4), 694-713. https://doi.org/10.1016/j.edurev.2019.100286

Salifu, I., Agbenyega, J. S., \& Practice, P. (2013). Teacher Motivation and Identity Formation: Issues Affecting Professional Practice. 3(1), 58-74.

Schutz, P. A., \& Hong, J. (n.d.). on Teacher Identity.

Upa, Y., \& Mbato, C. L. (2020). English Teacher Identity Construction: Indonesian Teachers' Motivation and Strategies in Teaching English for Special Needs Students. PROJECT (Professional Journal of English Education), 3(2), 311. https://doi.org/10.22460/project.v3i2.p311-321 